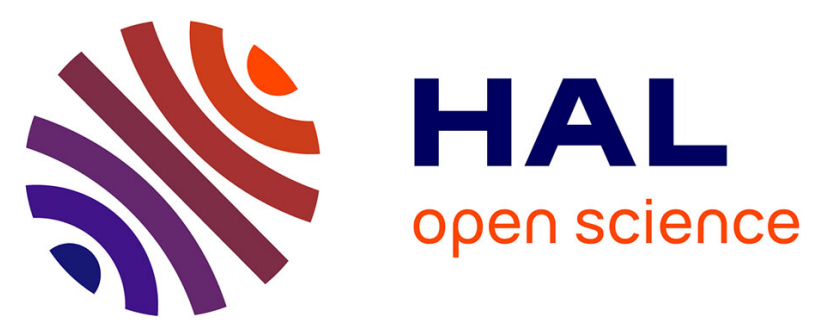

\title{
Suspended Particulate Matter Collection Methods influence the Quantification of Polycyclic Aromatic Compounds in the River System
}

Fayez Abuhelou, Laurence Mansuy, Catherine Lorgeoux, Delphine Catteloin, Valéry Collin, Allan Bauer, Hussein Jaafar Kanbar, Renaud Gley, Luc

Manceau, Fabien Thomas, et al.

\section{To cite this version:}

Fayez Abuhelou, Laurence Mansuy, Catherine Lorgeoux, Delphine Catteloin, Valéry Collin, et al.. Suspended Particulate Matter Collection Methods influence the Quantification of Polycyclic Aromatic Compounds in the River System. Environmental Science and Pollution Research, 2017, 24 (28), pp.22717-22729. 10.1007/s11356-017-9840-5 . hal-01760448

\section{HAL Id: hal-01760448 \\ https://hal.univ-lorraine.fr/hal-01760448}

Submitted on 6 Apr 2018

HAL is a multi-disciplinary open access archive for the deposit and dissemination of scientific research documents, whether they are published or not. The documents may come from teaching and research institutions in France or abroad, or from public or private research centers.
L'archive ouverte pluridisciplinaire HAL, est destinée au dépôt et à la diffusion de documents scientifiques de niveau recherche, publiés ou non, émanant des établissements d'enseignement et de recherche français ou étrangers, des laboratoires publics ou privés. 


\title{
Suspended Particulate Matter Collection Methods influence the Quantification of Polycyclic Aromatic Compounds in the River System
}

\author{
Fayez Abuhelou ${ }^{1}$, Laurence Mansuy-Huault ${ }^{1}$, Catherine Lorgeoux ${ }^{2}$, Delphine Catteloin ${ }^{2}$, Valéry Collin ${ }^{1}$, \\ Allan Bauer ${ }^{1}$, Hussein Jaafar Kanbar ${ }^{1}$, Renaud Gley ${ }^{1}$, Luc Manceau ${ }^{3}$, Fabien Thomas ${ }^{1}$, Emmanuelle \\ Montargès-Pelletier ${ }^{1}$. \\ ${ }^{1}$ Laboratoire Interdisciplinaire des Environnements Continentaux, CNRS-Université de Lorraine-LTER-Zone \\ Atelier Moselle, 54500 Vandœuvre-lès-Nancy, France. \\ ${ }^{2}$ GeoRessources UMR 7359, CNRS-Université de Lorraine-CREGU, BP239, 54506 Vandœuvre-lès-Nancy, France. \\ ${ }^{3}$ Laboratoire d'Observation des Territoires, Université de Lorraine, Ile du Saulcy, F-57045 Metz 01, France \\ a \\ b \\ Université de Lorraine, LIEC, UMR7360, Vandœuvre-lès-Nancy 54506, France \\ CNRS, LIEC, UMR7360, Vandœuvre-lès-Nancy 54506, France \\ Université de Lorraine, CNRS, CREGU, GeoRessources lab, UMR7359, Vandœuvre-lès-Nancy 54506, \\ France
}

\section{Corresponding author : L. Mansuy-Huault \\ laurence.huault@univ-lorraine.fr \\ Tel : +(33) 372745525}

\section{Abstract}

In this study, we compared the influence of two different collection methods, filtration (FT) and continuous flow field centrifugation (CFC) on the concentration and the distribution of polycyclic aromatic compounds (PACs) in suspended particulate matter (SPM) occurring in river waters. SPM samples were collected simultaneously with FT and $\mathrm{CFC}$ from a river during six sampling campaigns over two years, covering different hydrological contexts. SPM samples were analyzed to determine the concentration of PACs including 16 polycyclic aromatic hydrocarbons (PAHs), 11 oxygenated PACs (O-PACs) and 5 nitrogen PACs (N-PACs). Results showed significant differences between the two separation methods. In half of the sampling campaigns, PAC concentrations differed from a factor 2 to 30 comparing FT and CFC collected SPMs. The PAC distributions were also affected by the separation method. FT-collected SPM were enriched in 2-3 ring PACs whereas CFC-collected SPM had PAC distributions dominated by medium to high molecular weight compounds typical of combustion processes. This could be explained by distinct cut-off threshold of the two separation methods and strongly suggested the retention of colloidal and/or fine matter on glass-fiber filters particularly enriched in low molecular PACs. These differences between FT and CFC were not systematic but rather enhanced by high water flow rates. 
40 Keywords: Continuous Flow Centrifuge, Filtration, Polycyclic Aromatic Compounds, Suspended Particulate Matter. 
43 PACs constitute a wide group of organic micropollutants, ubiquitous in aquatic environments. They include the 16

44 PAHs identified as priority pollutants by the United States Environmental Protection Agency due to their mutagenic

45 and carcinogenic properties (Keith and Telliard 1979) (e.g. benzo(a)pyrene, benzo(a)anthracene, chrysene, 46 benzo(b)fluoranthene, benzo(k)fluoranthene, indeno(123-cd)pyrene and dibenzo(a,h)anthracene). PAHs

47 originate from pyrolytic or petrogenic sources and are used as markers of combustion processes, fuel spills or tar-oil

48 contaminations to trace inputs in the environment. Among PACs, oxygen (O-PACs) and nitrogen (N-PACs)

49 containing polycyclic aromatic compounds are emitted from the same sources as PAHs but can also be the products

50 of photochemical, chemical or microbial degradation of PAHs (Kochany and Maguire 1994; Bamford and Baker

51 2003; Tsapakis and Stephanou 2007; Lundstedt et al. 2007 ; Biache et al. 2017). These polar PACs have recently

52 received increasing attention in the monitoring of coking plant sites because of their toxicity. More soluble than their

53 parent PAHs, their transfer from soil to river should be enhanced but reports on their occurrence in aquatic

54 environments are scarce (Qiao et al. 2014; Siemers et al. 2015).

PACs enter the river systems through gas exchange at the air-water interface for the most volatile compounds, or associated to soot particles for the high molecular weight PACs, through atmospheric deposition and run-off or leaching of terrestrial surfaces (Cousins et al. 1999; Heemken et al. 2000; Countway et al. 2003; Gocht et al. 2007). These compounds partition among the entire water column, depending on their physical-chemical properties (solubility, vapor pressure, and sorption coefficient), and the hydrologic conditions in the river (Zhou et al. 1999). The low molecular weight PAHs are found in the dissolved phase whereas the high molecular PAHs are associated to particulate or colloidal matter (Foster et al. 2000; Countway et al. 2003). Although less studied than the sediments or the dissolved phase of the water column, the suspended particulate matter (SPM) plays a major role in the transport and fate of hydrophobic micropollutants in rivers and numerous studies focus on their characterization (Fernandes et al. 1997; Bianchi et al. 2007; Patrolecco et al. 2010; Maioli et al. 2011; Chiffre et al. 2015; Le Meur et al. 2017). In this perspective, the reliability of the process of sampling collection is a crucial prerequisite to ensure the quality of the analyses and the conclusions that can be drawn from their study.

Several methods are used to collect SPM from aquatic systems (e.g. Bates et al. 1983; Rossé et al. 2006; Ademollo et al. 2012). Sediment traps and field continuous flow centrifugation rely on the size and density properties of particles 
to promote their separation from water, similarly to sedimentation occurring in natural systems. Both methods offer

\section{Characteristics of sampling sites}

93 The Orne River is a left side tributary of the Moselle River, northeast of the Lorraine region, France (Fig 1). It is a the advantage of extracting SPM from a large volume of water (several hundred liters) and then provide a large amount of SPM, statistically representative because it integrates a large time window of at least several hours. Filtration is the most widespread technique used for SPM collection since it is easy to handle on the field and in the lab. The separation is controlled by the pore size of the filters. It is generally performed on small volumes that represent only a snapshot of river water. Several studies have pointed out the advantages and drawbacks of the different techniques. The distribution of organic compounds between dissolved and particulate phases is strongly affected by the separation technique. An overestimate of organic compounds in the particulate phase can be observed when SPM are separated with filtration, assigned to the colloid clogging of the membrane during filtration but these differences seem to depend on the amounts of suspended solids, the organic matter content as well as the ionic strength in the river (Bates et al. 1983; Morrison and Benoit 2001; Rossé et al. 2006; Ademollo et al. 2012). Anyway, most of the studies focus on the total concentrations of organic compounds in SPM and seldom discuss the influence of the separation techniques on the distribution of organic compounds although these distributions are often used to trace their origin such as in the case of PAHs.

In that perspective, we analyzed the concentration and the distribution of PACs in SPM collected in a river affected for more than one century by intense industrial activities (iron ore mining and steel-making plants) and the associated urbanization. Two sampling methods were compared i.e. field continuous flow centrifugation (CFC) and filtration on glass-fiber filters (FT). The study covered different hydrological situations and several sampling sites where the two sampling methods were applied. Two groups of PACs were explored: 16 PAHs representing a group of hydrophobic compounds $\left(3.3<\log \mathrm{K}_{\mathrm{ow}}<6.75\right)$ and 11 oxygenated and 5 nitrogen PACs, which represent a class of meanly hydrophobic properties $\left(2<\log \mathrm{K}_{\mathrm{ow}}<5.32\right)$. 
averaged flow fluctuates between 1.5 and $19 \mathrm{~m}^{3} \mathrm{~s}^{-1}$ with a mean flow of $8.1 \mathrm{~m}^{3} \mathrm{~s}^{-1}$ and maximum flow rates reaching at $170 \mathrm{~m}^{3} \mathrm{~s}^{-1}$. This river has been highly impacted by iron ore extraction and steel-making industries during the whole

$20^{\text {th }}$ century. Five different sampling sites were chosen based on criteria of representativeness and accessibility for

the field continuous flow centrifuge in the lower part of the Orne river, on the last $23 \mathrm{~km}$ before the confluence with the Moselle River: Auboué (AUB), Homécourt (BARB), Joeuf (JOAB), Moyeuvre-Grande (BETH) and Richemont (RICH). BETH site at Moyeuvre-Grande is located at a dam that influences the river hydrology: the water depth ranges between 3 and $4 \mathrm{~m}$ while it is meanly $1 \mathrm{~m}$ at the other sites and the water speed $\left(<0.5 \mathrm{~m} \mathrm{~s}^{-1}\right.$ at the dam) is 1.5 to 5 times lower than at other sites.

SPM were collected at six periods of time between May 2014 and May-June 2016 covering different hydrological situations (Table 1). The field continuous flow centrifugation (CFC) and filtration (FT) were applied to obtain $\mathrm{SPM}_{\mathrm{CFC}}$ and $\mathrm{SPM}_{\mathrm{FT}}$ respectively. Additionally, in May and June 2016, water samples from the inlet and outlet of the CFC were collected and filtered back in the laboratory, to obtain $\mathrm{SPM}_{\mathrm{FT} \mathrm{In-CFC}}$ and $\mathrm{SPM}_{\mathrm{FT}}$ Out-CFC.

The CFC operation, as already mentioned by Le Meur et al. (2015), started with river water being pumped to the mobile CFC (CEPA Z-41 running at 20000 RPM, equivalent to $17.000 \times \mathrm{g}$ ), located $10-50 \mathrm{~m}$ beside the river. The

111 CFC feeding flow rate was set to $600 \mathrm{~L} \mathrm{~h}^{-1}$. The cut-off threshold of the field centrifuge was shown to be close to 5 $112 \mu \mathrm{m}$ by measuring the grain-size of waters at the outlet of the centrifuge.m Depending on the campaign, the CFC was 113 run between $1 \mathrm{~h} 30$ and $3 \mathrm{~h}$ in order to obtain representative samples in sufficient amounts (from several grams to 100 $114 \mathrm{~g}$ of dry matter). The $\mathrm{SPM}_{\mathrm{CFC}}$ was recovered from the Teflon plates covering the internal surface of the centrifuge 115 bowl and transferred into glass bottles, transported to the lab in an ice-box to be immediately frozen, freeze-dried and 116 stored at $4^{\circ} \mathrm{C}$ for further use.

117 Depending on the water turbidity, and in order to collect sufficient amount of $\mathrm{SPM}_{\mathrm{FT}}$ on filters, $7.5 \mathrm{~L}$ of water were 118 collected in amber glass bottles and when necessary, additional 10 or $20 \mathrm{~L}$ were collected. All water samples were 119 brought back to the lab and filtered within $24 \mathrm{~h}$. To facilitate the filtration process, especially for high turbidity samples, waters were filtered sequentially on pre-weighted glass fiber filters, first on GFD (Whatman, $90 \mathrm{~mm}$ 121 diameter, nominal pore $\operatorname{size}=2.7 \mu \mathrm{m}$ ) followed by GFF (Whatman, $90 \mathrm{~mm}$ diameter, nominal pore size $=0.7 \mu \mathrm{m}$ ). 
123 SPM content on each filter in $\mathrm{mg} \mathrm{L}^{-1}$ was determined as the difference between the filter weight before and after

124 filtration process.

\section{Analytical methods}

Water temperature, electric conductivity (EC) and turbidity were measured using a portable multiparameter device (Hach ${ }^{\circledR}$ ). The Dissolved Organic Carbon (DOC) was measured with an automated total organic C analyzer (TOC130 VCPH. Shimadzu, Japan) on filtered water $\left(0.22 \mu \mathrm{m}\right.$ syringe filters) stored in brown glass flasks at $4^{\circ} \mathrm{C}$. The 131 Particulate Organic Carbon (POC) was determined on the carbonate-free freeze-dried samples of $\mathrm{SPM}_{\mathrm{CFC}}(1 \mathrm{M} \mathrm{HCl}$; 132 left to stand $1 \mathrm{~h}$; shaken $0.5 \mathrm{~h}$ ) and measured using a CS Leco SC144 DRPC analyzer and/or a CS Horiba 133 EMIA320V2 analyzer at SARM-CRPG Laboratory. The grain size distribution of particles in raw waters (except for 134 the campaign of May 2014) was determined using laser diffraction (Helos, Sympatec). The raw waters were introduced into the Sucell dispersing unit and were ultrasonicated for 20 seconds. Duplicate or triplicate measurements were performed to improve the measurement quality with and without ultrasound treatment. The particle size distribution was then represented as volumetric percentage as a function of particle diameter. In addition, the percentiles (Di) of the particles were calculated using Helos software. Di is the $\mathrm{i}^{\text {th }}$ percentile, i.e. the particle diameter at which $\mathrm{i} \%$ of the particles in the sample is smaller than Di (in $\mu \mathrm{m}$ ).

Up to $2 \mathrm{~g}$ of dry matter of $\mathrm{SPM}_{\mathrm{CFC}}$ and from 0.06 to $1.4 \mathrm{~g}$ of dry matter $\mathrm{SPM}_{\mathrm{FT}}$ were extracted with an Accelerated Solvent Extractor (Dionex® ASE350). ASE cells were filled with activated copper powder (to remove molecular sulphur) and sodium sulfate $\left(\mathrm{Na}_{2} \mathrm{SO}_{4}\right.$ to remove remaining water) and pre-extracted for cleaning. Samples were 144 extracted at $130^{\circ} \mathrm{C}$ and 100 bars with dichloromethane (DCM) with two cycles of 5 min (Biache et al. 2008). After 145 adjusting the volume at $5 \mathrm{~mL}$, a $1 \mathrm{~mL}$ aliquot was taken out for clean-up step. It was spiked with external extraction standards (mixture of 6 deuterated compounds: $\left[{ }^{2} \mathrm{H}_{8}\right]$ Dibenzofuran, $\left[{ }^{2} \mathrm{H}_{10}\right]$ Fluorene, $\left[{ }^{2} \mathrm{H}_{10}\right]$ Anthracene, 
$147\left[{ }^{2} \mathrm{H}_{8}\right]$ Anthraquinone, $\left[{ }^{2} \mathrm{H}_{10}\right]$ Fluoranthene, $\left[{ }^{2} \mathrm{H}_{12}\right]$ Benzo[ghi]perylene) to control the loss during the sample

148 preparation. The $1 \mathrm{~mL}$ aliquot was then evaporated to dryness using a gentle $\mathrm{N}_{2}$ flow, diluted into $200 \mu \mathrm{L}$ of hexane 149 and transferred onto the top of a silica gel column pre-conditioned with hexane. The aliphatic fraction was eluted using $3.5 \mathrm{~mL}$ of hexane. PAC fraction was eluted with $2.5 \mathrm{~mL}$ of hexane/DCM $(65 / 35 ; v / v)$ and $2.5 \mathrm{~mL}$ of methanol/DCM $(50 / 50 ; v / v)$. The latter fraction was spiked with $20 \mu \mathrm{L}$ at $12 \mu \mathrm{g} \mathrm{mL} \mathrm{L}^{-1}$ of internal quantification

152 standards (mixture of 8 deuterated compounds: $\left[{ }^{2} \mathrm{H}_{8}\right]$ Naphthalene, $\left[{ }^{2} \mathrm{H}_{10}\right]$ Acenaphthene, $\left[{ }^{2} \mathrm{H}_{10}\right]$ Phenanthrene, $153\left[{ }^{2} \mathrm{H}_{10}\right]$ Pyrene, $\left[{ }^{2} \mathrm{H}_{12}\right]$ Chrysene, $\left[{ }^{2} \mathrm{H}_{12}\right]$ Perylene and $\left[{ }^{2} \mathrm{H}_{8}\right] 9 \mathrm{H}$-fluorenone) before evaporation and the volume was 154 adjusted to $100 \mu \mathrm{L}$ with DCM. To improve the chromatographic resolution, the sample was derivatized by adding 155 BSTFA in $(1: 1 ; \mathrm{v} / \mathrm{v})$ and finally injected in $200 \mu \mathrm{L}$ volume in the gas chromatograph-mass spectrometer (GC-MS).

Analysis

The instrument used was an Agilent 6890N gas chromatograph equipped with a DB 5-MS column $(60 \mathrm{~m} \times 0.25 \mathrm{~mm}$ i.d. $\times 0.25 \mu \mathrm{m}$ film thickness) coupled with an Agilent 5973 mass selective detector operating in single ion monitoring mode. The molecules were detected with a quadrupole analyzer following ionization by electronic impact. The temperature program was the following: from $70^{\circ} \mathrm{C}$ to $130^{\circ} \mathrm{C}$ at $15^{\circ} \mathrm{C} \mathrm{min}^{-1}$, then from $130^{\circ} \mathrm{C}$ to $315^{\circ} \mathrm{C}$ at $3^{\circ} \mathrm{C} \min ^{-1}$ and then a $15 \mathrm{~min}$ hold at $315^{\circ} \mathrm{C} .1 \mu \mathrm{L}$ of sample was injected in splitless mode at $300^{\circ} \mathrm{C}$. The carrier gas was helium at $1.4 \mathrm{~mL} \mathrm{~min}^{-1}$ constant flow.

\section{Validation and quality control}

The quantitative analyses of PACs were carried out using internal calibration using specific family standard (refer to supporting information S1). For each quantified compound, the GC/MS was calibrated between 0.06 and $9.6 \mu \mathrm{g} \mathrm{mL}^{-1}$ with 10 calibration levels. The calibration curves were drawn and satisfactory determination coefficients were obtained $\left(r^{2}>0.99\right)$. To verify the quantification, two calibration controls (lower and higher concentrations) were carried out every 6 samples and only a deviation lower than $20 \%$ was accepted. The limits of quantification (LOQ) 169 for an extraction of $1 \mathrm{~g}$ of sample were between 0.06 and $0.12 \mu \mathrm{g} \mathrm{g}^{-1}$ (refer to supporting information S1). 170 Experimental and analytical blanks were also monitored regularly to assess external contamination.

171 The whole analytical procedure was validated using reference materials (SRM 1941a, NIST) for PAHs. For O-PAC 172 and N-PAC analysis, no commercial reference material was available. So the laboratory took part to an 

intercomparison study on the analysis of O-PAC and N-PAC in contaminated soils (Lundstedt et al. 2014). The

174 methodology was then adapted to sediment and SPM. The recoveries of external standards, added in each sample, 175 were checked and the quantification was validated if it ranged between 60 and $125 \%$ (refer to supporting 176 information S2).

\section{Results}

The global parameters (Table 1) exhibited different hydrological situations in the successive sampling campaigns. May 2014 and October 2015 corresponded to the lowest flow conditions with a daily mean water discharge around $1.5 \mathrm{~m}^{3} \mathrm{~s}^{-1}$ and rather high water temperature $\left(13\right.$ to $\left.17^{\circ} \mathrm{C}\right)$. The turbidity and the SPM contents were respectively lower than $3 \mathrm{NTU}$ and $6 \mathrm{mg} \mathrm{L}^{-1}$. The water discharge in May 2015 ranged between 8 and $21 \mathrm{~m}^{3} \mathrm{~s}^{-1}$ with turbidity values around $30 \mathrm{NTU}$ and SPM contents from 16 to $54 \mathrm{mg} \mathrm{L}^{-1}$. Higher water discharges, although rather moderate compared to that of a biennial flood reaching $130 \mathrm{~m}^{3} \mathrm{~s}^{-1}$, were observed in November $2014\left(22 \mathrm{~m}^{3} \mathrm{~s}^{-1}\right.$ the first day and $51 \mathrm{~m}^{3} \mathrm{~s}^{-1}$ the second day) and February $2015\left(50 \mathrm{~m}^{3} \mathrm{~s}^{-1}\right)$. The highest flow rates of $120 \mathrm{~m}^{3} \mathrm{~s}^{-1}$ were observed during the flood of May 2016. The highest turbidity and SPM content were observed during the first high flow of the season the $5^{\text {th }}$ of November 2014 (109 NTU and $122 \mathrm{mg} \mathrm{L}^{-1}$ ) and during the flood of May 2016 (94 NTU and $90 \mathrm{mg}$

190 May 2014. DOC varied between 4 and $11 \mathrm{mg} \mathrm{L}^{-1}$ with the highest DOC observed in May 2015 and the $5^{\text {th }}$ November 191 2014. Concerning, the grain size distribution of raw waters, the decile D50 was shown to vary very slightly from 5 to $19215 \mu \mathrm{m}$ for the different reported campaigns. The lowest value of the D50 $(\approx 5 \mu \mathrm{m})$ was measured in February 2015 193 during a high flow event (Table 1 and Fig 2). The measured particle size distributions covered relatively narrow 194 ranges from 1.5 to $102 \mu \mathrm{m}$ and the increases of the flow regime resulted in a clear increase of particle loading (SPM 195 content) with no strong shift of particle size. 
197 Table 2 displays the contents in PAHs, O-PACs and N-PACs and the main characteristics of their distribution according to the sampling methods (CFC and FT) and to the sampling dates and locations. The comparison of the 16 $\mathrm{PAH}$ concentrations in $\mathrm{SPM}_{\mathrm{FT}}$ and $\mathrm{SPM}_{\mathrm{CFC}}$ revealed a contrasted effect of the separation techniques.

When the whole set of data is considered, the sum of the $16 \mathrm{PAH}$ concentrations in $\mathrm{SPM}_{\mathrm{CFC}}$ ranged between 2 and $27.7 \mu \mathrm{g} \mathrm{g}^{-1}$ with a median value at $4 \mu \mathrm{g} \mathrm{g}^{-1}$. Despite a high value measured at JOAB site on May 2014, the range of variations was rather narrow, the $1^{\text {st }}$ and $3^{\text {rd }}$ quartiles being at 3.6 and $5.3 \mu \mathrm{g} \mathrm{g}^{-1}$ respectively (Fig 3a). For SPM $\mathrm{FT}_{\mathrm{F}}$ samples, the PAH concentrations varied between 1.3 and $39 \mu \mathrm{g} \mathrm{g}^{-1}$ with a median value at $18.4 \mu \mathrm{g} \mathrm{g}^{-1}$ but a higher dispersion of the PAH concentrations was observed, the $1^{\text {st }}$ and $3^{\text {rd }}$ quartiles being at 7.2 and $3.4 \mu \mathrm{g} \mathrm{g}^{-1}$ respectively (Fig. 3b). For all samples, O-PAC and N-PAC concentrations were much lower than PAHs, accounting for 10 to $30 \%$ of the total PACs except for BETH site in May 2014. The differences of O-PAC concentrations in SPM $_{\mathrm{FT}}$ and $\mathrm{SPM}_{\mathrm{CFC}}$ were also less contrasted. They were in a very close range, between 0 and $5.4 \mu \mathrm{g} \mathrm{g}^{-1}$ and 0.1 and $3.8 \mu \mathrm{g} \mathrm{g}^{-1}$ respectively in $\mathrm{SPM}_{\mathrm{FT}}$ and $\mathrm{SPM}_{\mathrm{CFC}}$. However, as observed for PAHs, the dispersion of the O-PAC concentrations was higher in $\mathrm{SPM}_{\mathrm{FT}}$ than in $\mathrm{SPM}_{\mathrm{CFC}}$ (Fig 2c and 2d).

210 The discrepancies in PAC concentrations between $\mathrm{SPM}_{\mathrm{FT}}$ and $\mathrm{SPM}_{\mathrm{CFC}}$ appeared more clearly when sampling campaigns were distinguished. The ratios of the PAH concentrations in $\mathrm{SPM}_{\mathrm{FT}}$ and $\mathrm{SPM}_{\mathrm{CFC}}$ (Fig. 4a) and of the polar PAC concentrations in $\mathrm{SPM}_{\mathrm{FT}}$ and $\mathrm{SPM}_{\mathrm{CFC}}$ (Fig. 4b) were calculated for each sample in order to highlight the differences of concentration according to the separation method and the sampling campaign. The whole campaign of May 2015, JOAB in May 2014 and BARB in November 2014 provided comparable PAH concentrations in SPM FT and $\mathrm{SPM}_{\mathrm{CFC}}$ with a ratio close to 1. However, all the samples of February 2015 and May-June 2016, BETH in May 2014 and JOAB and BETH in November 2014 provided higher concentrations of PAHs with concentrations in $217 \mathrm{SPM}_{\mathrm{FT}}$ two to eleven times higher than in $\mathrm{SPM}_{\mathrm{CFC}}$ (Fig. 4a).

218 The comparison of polar PAC concentrations in $\mathrm{SPM}_{\mathrm{FT}}$ and $\mathrm{SPM}_{\mathrm{CFC}}$ also revealed discrepancies between the two sampling methods (Fig 3b). In February 2015 and May-June 2016, polar PACS were six to thirty times more concentrated in $\mathrm{SPM}_{\mathrm{FT}}$ than in $\mathrm{SPM}_{\mathrm{CFC}}$. In May 2014, polar PAC concentrations were fifteen times higher in $\mathrm{SPM}_{\mathrm{FT}}$ at BETH than in $\mathrm{SPM}_{\mathrm{CFC}}$. the 4 to 6 ring-PAHs were easily detected and well represented in the distribution, representing 50 to $90 \%$ of the all 
224 PAHs (except in May 2014), even though they could vary in abundance according to the sampling campaign (Table 225 2). In $\mathrm{SPM}_{\mathrm{FT}}, 2$ to 3 ring-PAHs were systematically more represented than in $\mathrm{SPM}_{\mathrm{CFC}}$ and accounted for 40 to $70 \%$ 226 of the total PAH concentration except during the November 2014 and May 2015 campaigns. The ratio of each 227 individual PAH concentration in $\mathrm{SPM}_{\mathrm{FT}}$ over its concentration in $\mathrm{SPM}_{\mathrm{CFC}}$ was plotted against the $\log K_{o w}$ of each 228 PAH for all the samples (Fig. 5). The ratio is close to 1 for the PAHs with $\log K_{o w}$ higher than 5.5 having more than 2294 aromatic rings whereas it can vary from 0.5 to 38 for PAHs with 2 to 4 aromatic rings $\left(\log K_{o w}<5.2\right)$. The highest 230 differences were observed in Feb 2015 and May-June 2016 and to a lesser extent in Nov 2014, May 2014 and 231 October 2015. Thus, it appeared that the 2 to 3-ring PAHs and to a lesser extent the 4-ring PAHs were the molecules 232 the most affected by the sampling methods.

233 In the same way, any time we observed a significant difference of O-PAC concentration between the two sampling 234 methods (February 2015 and May-June 2016), it could be attributed to a higher concentration in low molecular weight O-PACs, composed of three rings, mainly dibenzofuran, fluorenone and anthraquinone (Table 2).

Values of common PAH molecular ratios were compared (Table 2 and Fig. 6). Only, the ratios based on 3 and 4 rings could be calculated in $\mathrm{SPM}_{\mathrm{FT}}$ and compared to $\mathrm{SPM}_{\mathrm{CFC}}$. Whatever the sampling method, the values of Flt $/($ Flt + Pyr $)$ were found within a quite narrow range of $0.5-0.66$ assigned to pyrogenic inputs. The values of Ant/(Ant+Phe) evolved between 0.07 and 0.37 in SPM $_{\mathrm{CFC}}$ placing most of the samples in the pyrogenic domain and showing a variation in the contribution of these compounds according to the hydrology. Except for October 2015, the ratios $\mathrm{Ant} /(\mathrm{Ant}+\mathrm{Phe})$ in $\mathrm{SPM}_{\mathrm{FT}}$ ranging between 0.06 and 0.17 , were systematically lower than in the equivalent $\mathrm{SPM}_{\mathrm{CFC}}$ suggesting an influence of petrogenic PAHs.

\section{PACs in the filtered SPM of the inlet and outlet waters of the CFC}

245 The analyses of the matter collected by filtration of the inlet waters of CFC ( $\mathrm{SPM}_{\mathrm{FT}} \mathrm{In}$-CFC $)$ and the matter collected 246 by filtration of the outlet waters of the CFC (SPM $\mathrm{FT}_{\text {Out-CFC }}$ ) allowed to better understand the partitioning of SPM in 247 the CFC and then by the filtration process. This test was carried out at AUB, RICH and BETH in May and June 248 2016. The quantification of the SPM collected by filtration of the inlet and outlet waters showed that CFC allowed to 249 recover $80 \%$ of the SPM contained in the inlet waters (Table 3). In the three tests, as already described in the 
previous paragraphs, the PAH concentrations are six to eleven times higher in $\mathrm{SPM}_{\mathrm{FT}}$ than in $\mathrm{SPM}_{\mathrm{CFC}}$. The PAH

251 concentration in the residual SPM collected by filtration of the CFC outlet waters ( $\mathrm{SPM}_{\mathrm{FT}}$ Out-CFC) is as high or even 252 twice higher than in the inlet water. The PAH distributions displayed at figure 7 are representative of those observed 253 in most of the $\mathrm{SPM}_{\mathrm{FT}}$ and $\mathrm{SPM}_{\mathrm{CFC}}$. PAH distributions in $\mathrm{SPM}_{\mathrm{CFC}}$ are characterized by the abundance of 4 to 6-ring 254 PAHs whereas they are in very low abundance in $\mathrm{SPM}_{\mathrm{FT}}$ and not detectable in $\mathrm{SPM}_{\mathrm{FT}}$ Out-CFC. Thus, the CFC retains 255 SPM containing low PAC concentrations made of high molecular weight compounds and the SPM not retained by 256 the CFC but collected by the filtration of the outlet waters is highly concentrated in PACs mainly made of 257 phenanthrene, fluoranthene and pyrene. The PAH distribution in $\mathrm{SPM}_{\mathrm{FT}}$ In- CFC and $\mathrm{SPM}_{\mathrm{FT}}$ Out-CFC are very similar 258 showing that the contribution of the fine matter collected in the outlet waters largely contributes to the SPM collected 259 in the total SPM collected on filters (figure 7).

\section{Discussion}

262 Our results show that the two methods of SPM collection strongly influence not only the concentration but also the distribution of PACs. PACs in $\mathrm{SPM}_{\mathrm{CFC}}$ were found in a narrow range of concentrations independently of the sampling location and the hydrological situation. The PAH distributions were dominated by 4 to 6 ring- PAHs. On the contrary, in $\mathrm{SPM}_{\mathrm{FT}}$, the spreading of $\mathrm{PAH}$ concentrations was much higher, and the PAH distribution was dominated by low molecular weight compounds when a noticeable discrepancy was observed compared to SPM $_{\mathrm{CFC}}$. From reported results in literature, a non-exhaustive inventory of PAH concentrations and distributions according to the SPM collection method, regardless of the spatial and hydrological context was summarized on Table 4. This inventory shows that the concentrations remain in a relatively narrow range (the maximum concentration does not exceed five times the minimum concentration) when the SPM collection method is CFC (Wölz et al. 2010; Le Meur

271 et al. 2017) or sediment traps (Zhang et al. 2009; Chiffre et al. 2015) or pressure-enhanced filtration system 272 (Countway et al. 2003; Ko and Baker 2004). When the SPM are collected by filtration, the PAH concentration range 273 can be really more highly spread from one to 40 times (Deng et al., 2006; Guo et al., 2007; Luo et al., 2009; Maioli 274 et al., 2011; Mitra and Bianchi, 2003; Sun et al., 2009; Zheng et al., 2016). One can argue that this variation might 275 obviously depend on the river and the hydrological situation. However, if we compare the PAH distributions, it 276 clearly appears that whenever the sampling method is filtration, 2 to 3-ring PAHs can largely dominate the 

the low molecular weight PAHs seldom dominate the distribution.

279 Several studies have reported that filtration retains colloidal organic matter and their associated organic or metallic 280 contaminants leading to an overestimate of compounds associated to particulate matter. Bates et al. (1983) compared centrifugation and filtration to collect particulate matter from wastewaters and riverine waters and observed a systematic higher concentration of aliphatic hydrocarbons in SPM collected by filtration and a lower proportion of dissolved hydrocarbons in the filtered water compared to the centrifuged one. They attributed it to the adsorption of dissolved an colloidal matter on the glass-fiber filter and by the matter retained on its surface. Morrison and Benoit (2001) showed that membrane clogging during filtration of riverine waters induces the decline of dissolved cation concentrations in filtered waters. Our results show variations from a factor 2 to 9 for PAH contents and 2 to 30 for OPAC contents when SPM are separated by filtration and could be explained by the retention of colloidal and fine matter on filters. Gomez-Gutierrez et al. (2007) tested the adsorption of various organics on glass-fiber filters according to DOC values and salinity on synthetic waters. They showed an increase of the adsorption of the more hydrophobic PAHs (4 to 6 rings) with the increase of DOC and salinity but a lower adsorption of low molecular weight PAHs. In our natural waters, if we compare the PAC concentrations and distributions, we observed an opposite trend with low molecular weight PAHs being more concentrated in $\mathrm{SPM}_{\mathrm{FT}}$ than in $\mathrm{SPM}_{\mathrm{CFC}}$. The higher concentration in $\mathrm{SPM}_{\mathrm{FT}}$ cannot be only related to $\mathrm{PAH}$ adsorption on filters but might be due to the retention of colloidal or fine particulate matter (few microns), organic and mineral, particularly enriched in low molecular weight PAHs. This hypothesis is strongly supported by the abundance of low molecular weight PACs highly concentrated in the matter not retained by the centrifuge but collected by filtration of the outlet waters. Countway et al. (2003) showed that high molecular weight PAHs were rather associated to soot and particles from sediment resuspension whereas more volatile PAHs were associated to autochthonous organic matter. Wang et al. (2016) also observed enrichment in low molecular weight hydrocarbons in the finer grain-size fractions of their sediments. February 2015 and May and June 2016, the highest differences between $\mathrm{SPM}_{\mathrm{FT}}$ and $\mathrm{SPM}_{\mathrm{CFC}}$ are concomitant of a high flow and the finest grain size distribution of SPM $(\mathrm{D} 50<10 \mu \mathrm{m})$. In those cases, filtration allowed to recover 
collected coarser matter with much lower PAC concentrations (2 to $\left.5.5 \mu \mathrm{g} \mathrm{g}^{-1}\right)$. Previous studies observed similar trends in other contexts. Wang et al. (2016) showed that small-size SPM $(0,7-3 \mu \mathrm{m})$ collected from estuarine and riverine waters were particularly enriched in PAHs compared to large-size SPM ( $>3 \mu \mathrm{m})$. El-Mufleh et al. (2014) separated sediments from storm water infiltration basins into several density fractions and showed that the PAH amounts were 100 times higher in the lighter fractions than in the denser ones. In their study of colloids and SPM in river, Ran et al. (2000) showed the increasing content in organic carbon and ions with decreasing particle size and highlighted the importance of colloidal matter in the concentrations of micropollutants. However, in our set of data, no significant correlation could be observed between the high amount of PACs in SPM $\mathrm{FT}_{\mathrm{FT}}$ and global parameters such as particle grain-size, water discharge, organic carbon content of SPM, water conductivity or SPM amount.

313 This comparison of PACs in $\mathrm{SPM}_{\mathrm{FT}}$ and $\mathrm{SPM}_{\mathrm{CFC}}$ allowed evidencing the crucial role of colloidal and fine particulate matter in the transfer of PACs. The predominant contribution of fine and/or colloidal matter in $\mathrm{SPM}_{\mathrm{FT}}$ in February 2015 and May-June 2016 campaigns revealed that this matter transfers mainly low molecular weight PACs compared to the coarser particulate fraction collected by $\mathrm{SPM}_{\mathrm{CFC}}$. Also, the molecular ratios suggest a different origin for PACs in colloidal and fine matter with a higher contribution of petroleum products. This suggests that

318 distinct transfer paths of PACs coexist in this river: the PACs associated to particulate matter with a quite 319 homogeneous molecular signature assigned to combustion corresponding to diffuse pollution in the catchment and the PACs associated to colloidal and fine matter with a more variable molecular signature that could be assigned to petrogenic contribution and could enter the river as a point-source during specific hydrological events.

\section{Conclusions}

324 Filtration on glass fiber filters $(0.7 \mu \mathrm{m})$, the most commonly used technique, is easy to handle, inexpensive, adapted to any field context and the separation between particulate and dissolved matter is based on particle size. In this study, we showed that this method might collect colloidal and fine matter that can significantly affect the amount of

327 PACs measured in the SPM fraction inducing higher concentrations and distributions enriched in low molecular compounds. These differences were not systematic over the two-year period of our investigation in a small industrial river system. On the contrary, the second sampling technique we tested on the same samples, CFC, provided SPM a 

one site to another and from one hydrological condition to another. PAC distributions were dominated by medium to

332 high molecular weight compounds that allowed to calculate various diagnostic molecular ratios easier to interpret 333 than with FT where the poor abundance of HMW PAC limited the interpretation of molecular ratios. Although 334 filtration presents numerous advantages to collect SPM, one must be very careful in the interpretations of some 335 variations that can also be attributed to the retention of some colloidal and fine matter, enriched in low molecular 336 PACs, especially during high flow events. On the other hand, this allows to access to supplemental information on 337 the nature of PACs transported by fine and colloidal matter. Thus, according to the sampling method, evaluation of 338 PAC distribution between dissolved and particulate phase can be appreciably different. These results suggest that the 339 choice of a SPM collection method is fundamental to comply with the objectives that one can defined for the 340 monitoring of surface waters.

\section{Acknowledgements}

343 The authors would like to thank Long-Term Ecosystem Research (LTER) France, Agence Nationale de la Recherche 344 (ANR) project number ANR-14-CE01-0019, RésEAU LorLux and Region Lorraine through the research network of 345 Zone Atelier Moselle (ZAM) for partially funding the work, the Syndicat de Valorisation des Eaux de l'Orne 346 (SVEO) and the city of Moyeuvre for granting us access to the sampling sites. We thank ERASMUS MUNDUS for 347 funding the $\mathrm{PhD}$ of $\mathrm{M}$. Abuhelou. The final manuscript was also improved by the valuable suggestions of four 348 reviewers. 
Ademollo N, Patrolecco L, Polesello S, et al (2012) The analytical problem of measuring total concentrations of organic pollutants in whole water. TrAC Trends Anal Chem 36:71 - 81. doi: http://dx.doi.org/10.1016/j.trac.2012.01.008

Bamford HA, Baker JE (2003) Nitro-polycyclic aromatic hydrocarbon concentrations and sources in urban and suburban atmospheres of the Mid-Atlantic region. Atmos Environ 37:2077 - 2091. doi: http://dx.doi.org/10.1016/S1352-2310(03)00102-X

Bates TS, Hamilton SE, Cline JD (1983) Collection of Suspended Particulate Matter for Hydrocarbon Analyses: Continuous Flow Centrifugation vs. Filtration.

Biache C, Mansuy-Huault L, Faure P, et al (2008) Effects of thermal desorption on the composition of two coking plant soils: Impact on solvent extractable organic compounds and metal bioavailability. Environ Pollut 156:671-677. doi: 10.1016/j.envpol.2008.06.020

Biache C, Ouali S, Cébron A, et al (2017) Bioremediation of PAH-contamined soils: Consequences on formation and degradation of polar-polycyclic aromatic compounds and microbial community abundance. J Hazard Mater 329:1 10. doi: https://doi.org/10.1016/j.jhazmat.2017.01.026

Bianchi TS, Wysocki LA, Stewart M, et al (2007) Temporal variability in terrestrially-derived sources of particulate organic carbon in the lower Mississippi River and its upper tributaries. Geochim Cosmochim Acta 71:4425 - 4437. doi: http://dx.doi.org/10.1016/j.gca.2007.07.011

Chiffre A, Degiorgi F, Morin-Crini N, et al (2015) PAH occurrence in chalk river systems from the Jura region (France). Pertinence of suspended particulate matter and sediment as matrices for river quality monitoring. Environ Sci Pollut Res 22:17486-17498. doi: 10.1007/s11356-015-4897-5

Countway RE, Dickhut RM, Canuel EA (2003) Polycyclic aromatic hydrocarbon (PAH) distributions and associations with organic matter in surface waters of the York River, \{VA\} Estuary. Org Geochem 34:209 - 224. doi: http://dx.doi.org/10.1016/S0146-6380(02)00162-6

Cousins IT, Beck AJ, Jones KC (1999) A review of the processes involved in the exchange of semi-volatile organic compounds (SVOC) across the air-soil interface. Sci Total Environ 228:5 - 24. doi: http://dx.doi.org/10.1016/S0048-9697(99)00015-7

Deng H, Peng P, Huang W, Song J (2006) Distribution and loadings of polycyclic aromatic hydrocarbons in the Xijiang River in Guangdong, South China. Chemosphere 64:1401 - 1411. doi:

http://dx.doi.org/10.1016/j.chemosphere.2005.12.027

El-Mufleh A, Béchet B, Basile-Doelsch I, et al (2014) Distribution of PAHs and trace metals in urban stormwater sediments: combination of density fractionation, mineralogy and microanalysis. Environ Sci Pollut Res 21:97649776. doi: 10.1007/s11356-014-2850-7

Fernandes MB, Sicre M-A, Boireau A, Tronczynski J (1997) Polyaromatic hydrocarbon (PAH) distributions in the Seine River and its estuary. Mar Pollut Bull 34:857 - 867. doi: http://dx.doi.org/10.1016/S0025-326X(97)00063-5

Foster GD, Jr ECR, Gruessner B, Velinsky DJ (2000) Hydrogeochemistry and transport of organic contaminants in an urban watershed of Chesapeake Bay (USA). Appl Geochem 15:901 - 915. doi: http://dx.doi.org/10.1016/S08832927(99)00107-9

Gocht T, Ligouis B, Hinderer M, Grathwohl P (2007) Accumulation of polycyclic aromatic hydrocarbons in rural 
391 Gomez-Gutierrez A, Jover E, Bayona JM, Albaigès J (2007) Influence of water filtration on the determination of a wide range of dissolved contaminants at parts-per-trillion levels. Anal Chim Acta 583 2007 583:202-209.

393 Heemken PO, Stachel B, Theobald N, Wenclawiak WB (2000) Temporal Variability of Organic Micropollutants in 394 Suspended Particulate Matter of the River Elbe at Hamburg and the River Mulde at Dessau, Germany. Arch Environ 395 Contam Toxicol 38:11-31. doi: 10.1007/s002449910003

396 Keith L, Telliard W (1979) ES\&T Special Report: Priority pollutants: I-a perspective view. Environ Sci Technol 397 13:416-423. doi: 10.1021/es60152a601

Kochany J, Maguire RJ (1994) Abiotic transformations of polynuclear aromatic hydrocarbons and polynuclear aromatic nitrogen heterocycles in aquatic environments. Sci Total Environ 144:17 - 31. doi: http://dx.doi.org/10.1016/0048-9697(94)90424-3

Ko F-C, Baker JE (2004) Seasonal and annual loads of hydrophobic organic contaminants from the Susquehanna http://dx.doi.org/10.1016/j.marpolbul.2003.10.014

404 Le Meur M, Mansuy-Huault L, Lorgeoux C, et al (2017) Spatial and temporal variations of Particulate Organic Matter from Moselle River and tributaries: A multimolecular investigation.

Le Meur M, Montargès-Pelletier E, Bauer A, et al (2015) Characterization of suspended particulate matter in the Moselle River (Lorraine, France): evolution along the course of the river and in different hydrologic regimes. J Soils Sediments 1-18. doi: 10.1007/s11368-015-1335-8

Lundstedt S, Bandowe BAM, Wilcke W, et al (2014) First intercomparison study on the analysis of oxygenated polycyclic aromatic hydrocarbons (oxy-PAHs) and nitrogen heterocyclic polycyclic aromatic compounds (N-PACs) in contaminated soil. TrAC Trends Anal Chem 57:83 - 92. doi: http://dx.doi.org/10.1016/j.trac.2014.01.007 polycyclic aromatic hydrocarbons, organochlorine pesticides, and nonylphenols in a wetland. J Soils Sediments 9:180-187. doi: 10.1007/s11368-009-0081-1 aromatic hydrocarbons in suspended particulate matter in water from two Brazilian estuarine systems. Cont Shelf 
429 Qiao M, Qi W, Liu H, Qu J (2014) Oxygenated, nitrated, methyl and parent polycyclic aromatic hydrocarbons in 430 rivers of Haihe River System, China: Occurrence, possible formation, and source and fate in a water-shortage area.

431 Sci Total Environ 481:178 - 185. doi: http://dx.doi.org/10.1016/j.scitotenv.2014.02.050

432 Ran Y, Fu JM, Sheng GY, et al (2000) Fractionation and composition of colloidal and suspended particulate

433 materials in rivers. Chemosphere 41:33 - 43. doi: http://dx.doi.org/10.1016/S0045-6535(99)00387-2

434 Rossé P, Vignati D, Dominik J (2006) Effects of continuous flow centrifugation on measurements of trace elements 435 in river water: intrinsic contamination and particle fragmentation. Hydrol Process 20:2745-2754. doi:

$436 \quad 10.1002 /$ hyp.6064

437 Siemers A-K, Mänz JS, Palm W-U, Ruck WKL (2015) Development and application of a simultaneous SPE-method 438 for polycyclic aromatic hydrocarbons (PAHs), alkylated PAHs, heterocyclic $\{\mathrm{PAHs}\}$ (NSO-HET) and phenols in 439 aqueous samples from German Rivers and the North Sea. Chemosphere 122:105 - 114. doi:

440 http://dx.doi.org/10.1016/j.chemosphere.2014.11.022

441 Sun J-H, Wang G-L, Chai Y, et al (2009) Distribution of polycyclic aromatic hydrocarbons (PAHs) in Henan Reach 442 of the Yellow River, Middle China. Ecotoxicol Environ Saf 72:1614 - 1624. doi:

443 http://dx.doi.org/10.1016/j.ecoenv.2008.05.010

444 Tsapakis M, Stephanou EG (2007) Diurnal Cycle of PAHs, Nitro-PAHs, and oxy-PAHs in a High Oxidation 445 Capacity Marine Background Atmosphere. Environ Sci Technol 41:8011-8017. doi: 10.1021/es071160e

446 Wang X, Yuan K, Chen B, et al (2016) Monthly variation and vertical distribution of parent and alkyl polycyclic 447 aromatic hydrocarbons in estuarine water column: Role of suspended particulate matter. Environ Pollut 216:599 448 607. doi: http://dx.doi.org/10.1016/j.envpol.2016.06.018

449 Wölz J, Fleig M, Schulze T, et al (2010) Impact of contaminants bound to suspended particulate matter in the context 450 of flood events. J Soils Sediments 10:1174-1185. doi: 10.1007/s11368-010-0262-y

451 Zhang L, Zhang J, Gong M (2009) Size distributions of hydrocarbons in suspended particles from the Yellow River. 452 Appl Geochem 24:1168 - 1174. doi: http://dx.doi.org/10.1016/j.apgeochem.2008.12.033

453 Zheng B, Wang L, Lei K, Nan B (2016) Distribution and ecological risk assessment of polycyclic aromatic 454 hydrocarbons in water, suspended particulate matter and sediment from Daliao River estuary and the adjacent area, 455 China. Chemosphere 149:91 - 100. doi: http://dx.doi.org/10.1016/j.chemosphere.2016.01.039

456 Zhou JL, Fileman TW, Evans S, et al (1999) The partition of fluoranthene and pyrene between suspended particles 457 and dissolved phase in the Humber Estuary: a study of the controlling factors. Sci Total Environ 243-244:305 - 321. 458 doi: http://dx.doi.org/10.1016/S0048-9697(99)00404-0 


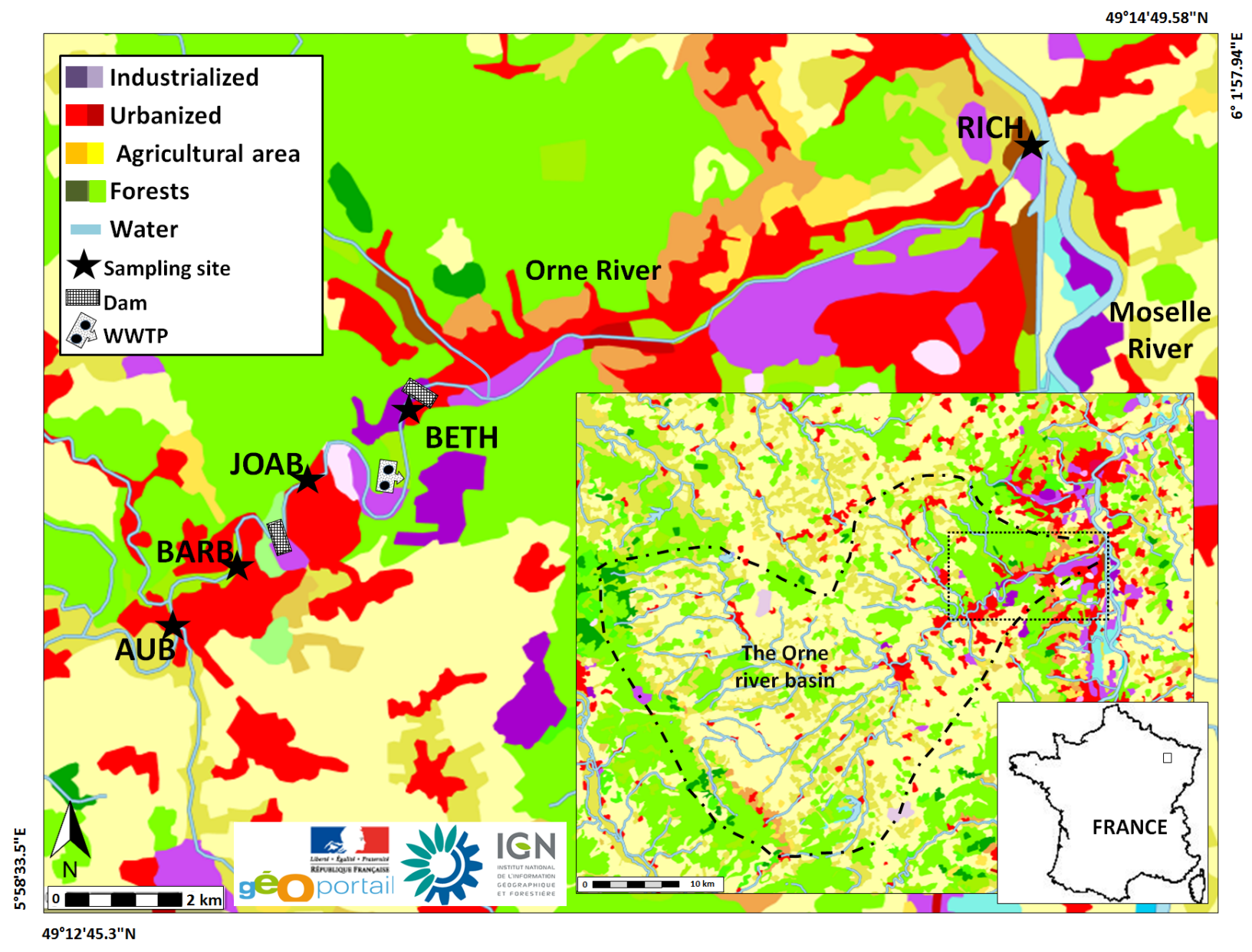

Fig. 1 Lower part of the Orne River catchment, showing the five selected sampling sites and the land cover and use (Map source: CORINE Land Cover, 2012). 


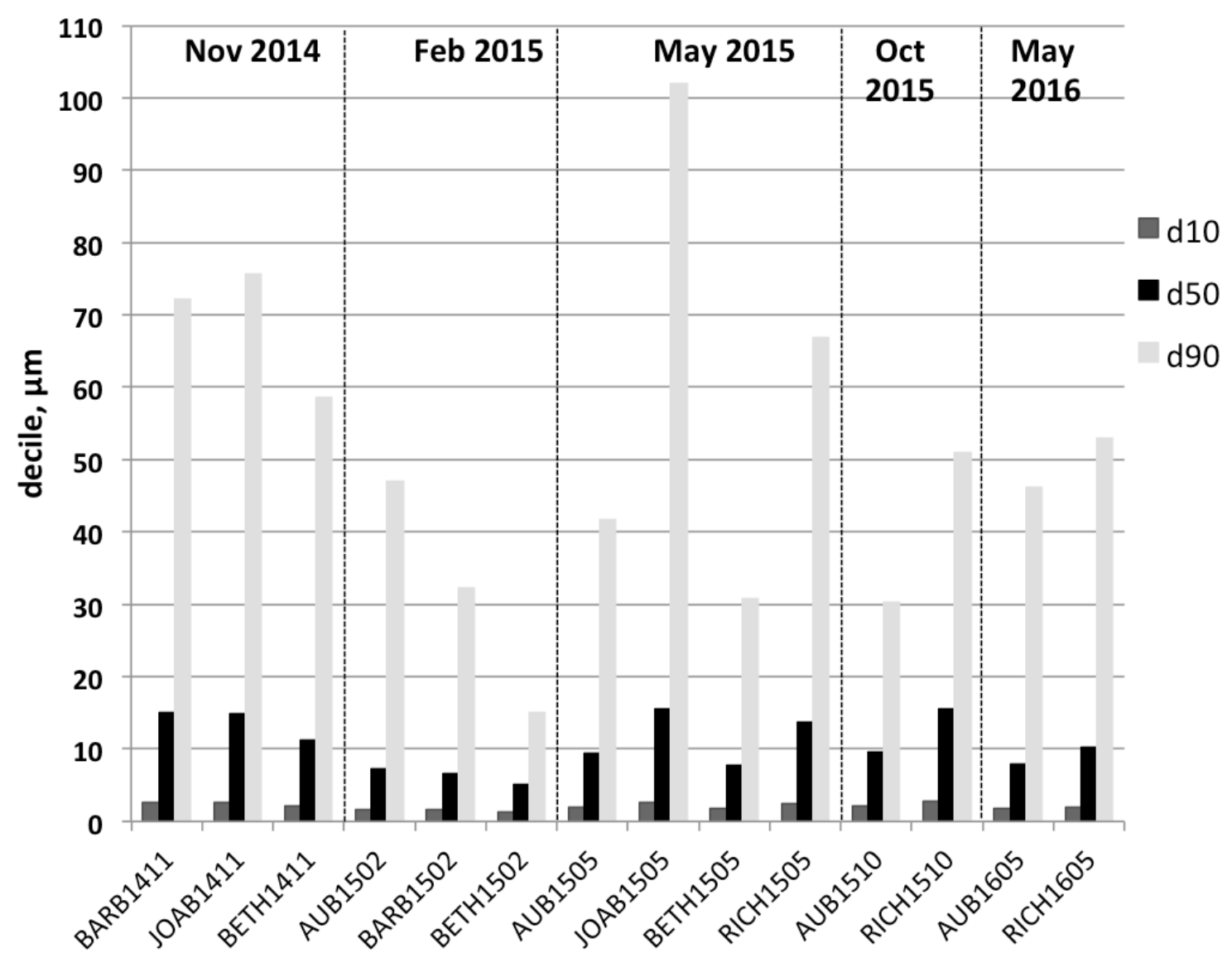

Fig. 2 Grain size distribution deciles (d10, d50 and d90) of raw waters measured for the campaigns from November 2014 to May 2016. 
a) PAHs in SPM

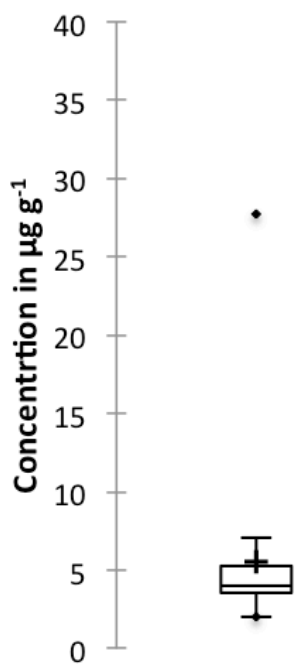

b) PAHs in SPM

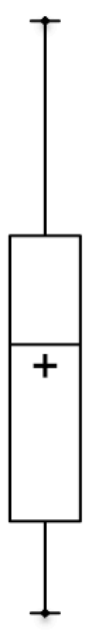

c) O-PACs in SPM $\mathrm{CFC}_{\mathrm{CF}}$

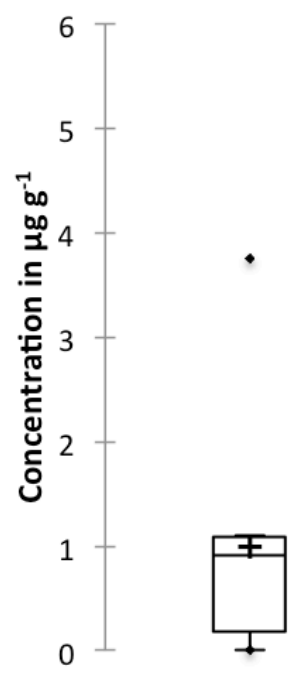

d) O-PACs in SPM

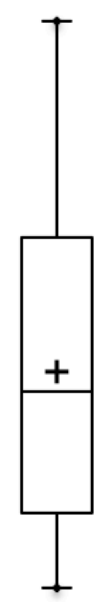

Fig. 3 Box plots of $\Sigma P A H$, and $\Sigma O-P A C$ concentrations in $\operatorname{SPM}_{\mathrm{CFC}}$ (a) and (c) and in $\mathrm{SPM}_{\mathrm{FT}}$ (b) and (d) for all samples. The boundaries of the box indicate the 25th and 75th percentiles; the line within the box marks the median; the + is the mean value; and values on the top and bottom of the box indicate the minimum and maximum of the distribution. 

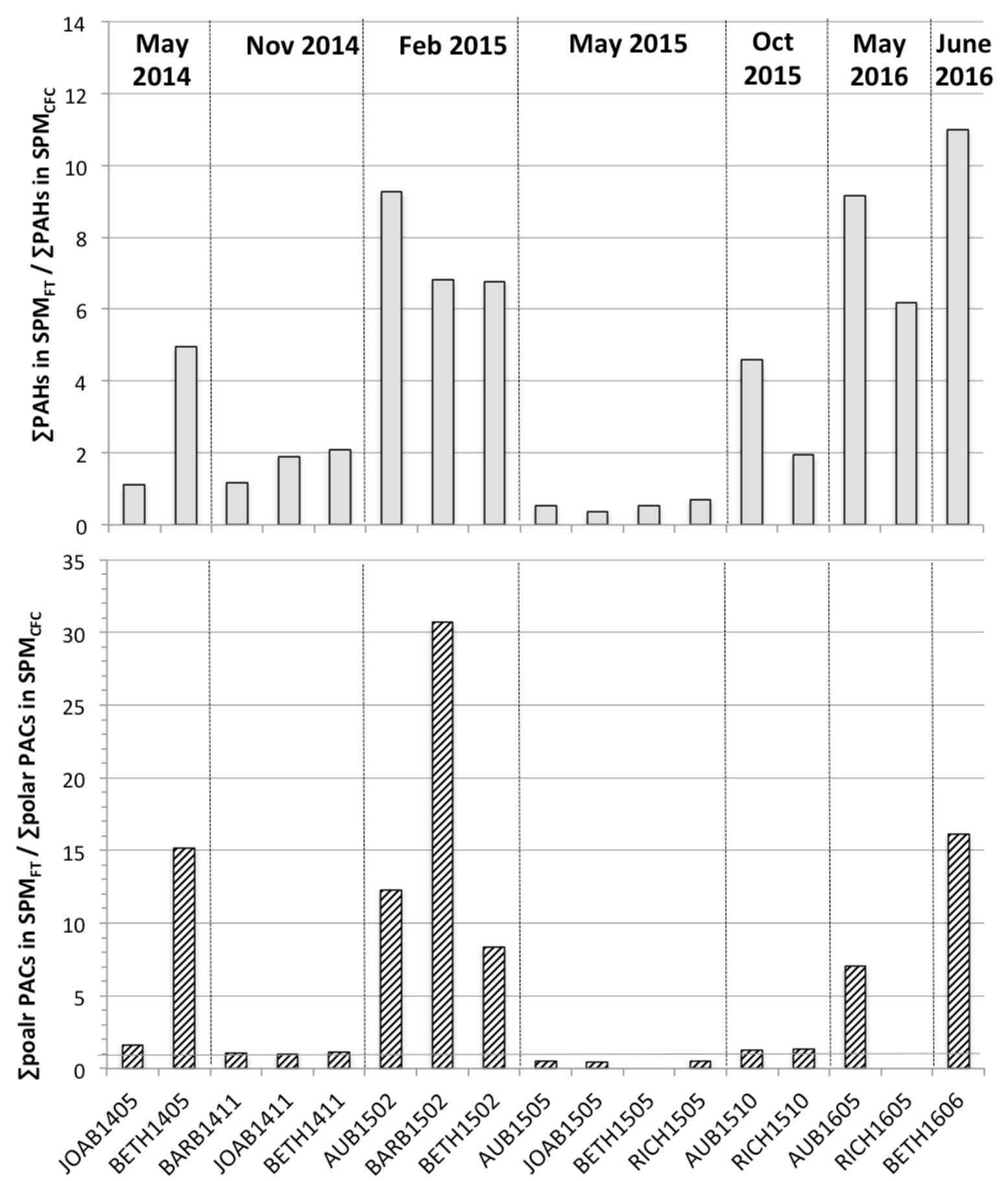

\section{Sampling campaigns}

Fig. 4 Comparison of the ratios of PAH content in $\mathrm{SPM}_{\mathrm{FT}}$ over PAH content in $\mathrm{SPM}_{\mathrm{CFC}}$ (a) and of polar PAC content (11 O-PACs 5 N-PACs) in $\mathrm{SPM}_{\mathrm{FT}}$ over polar PAC content in $\mathrm{SPM}_{\mathrm{CFC}}$ (b) for each sample of the campaigns. 


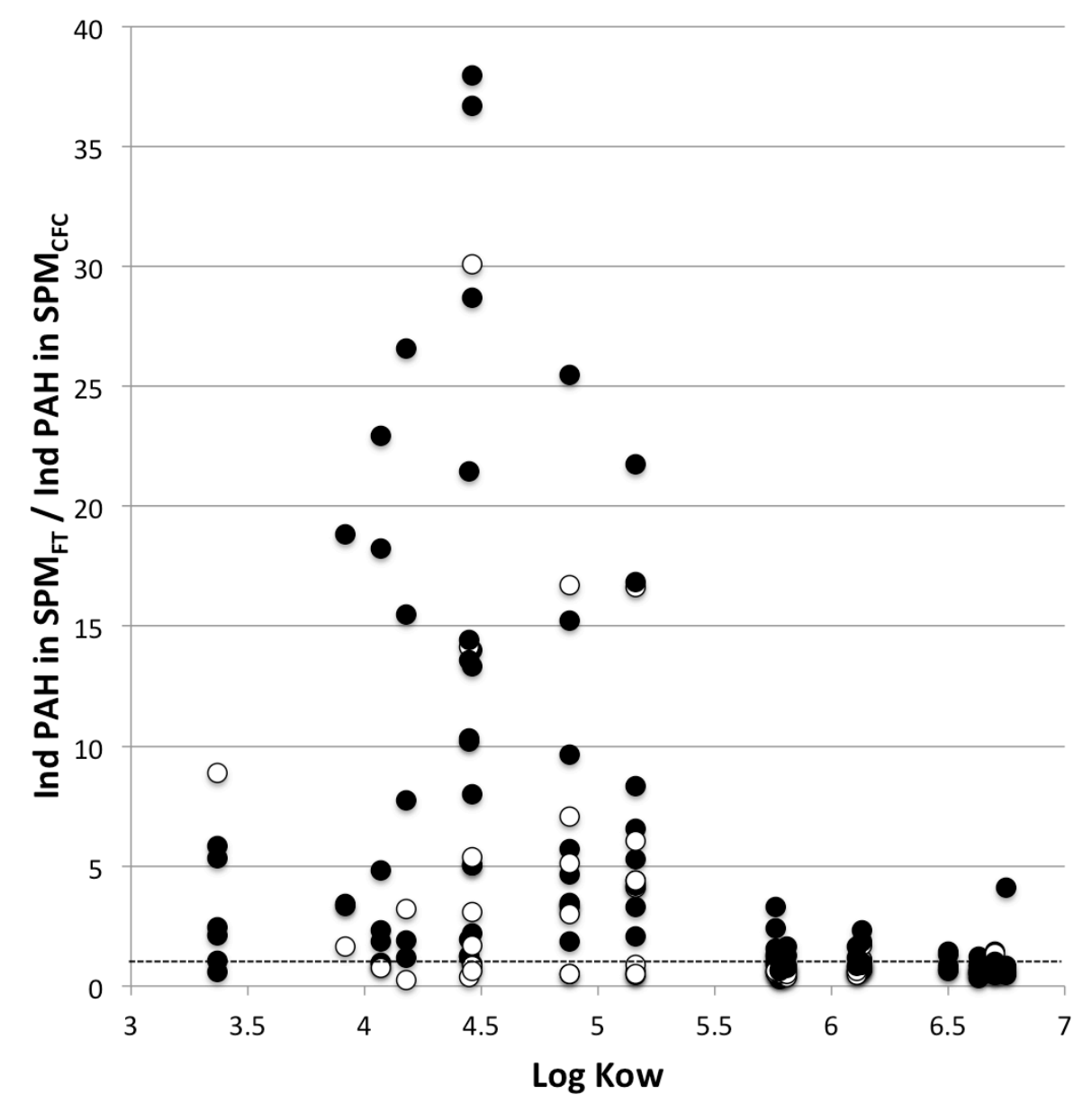

Fig. 5 Ratios of individual PAH concentration in $\mathrm{SPM}_{\mathrm{FT}}$ over their concentration in $\mathrm{SPM}_{\mathrm{CFC}}$ plotted against the $\log K_{o w}$ of these PAHs. Black circles represent the campaigns of November 2014, February 2015 and May-June 2016, and white circles represent the other sampling campaigns. 


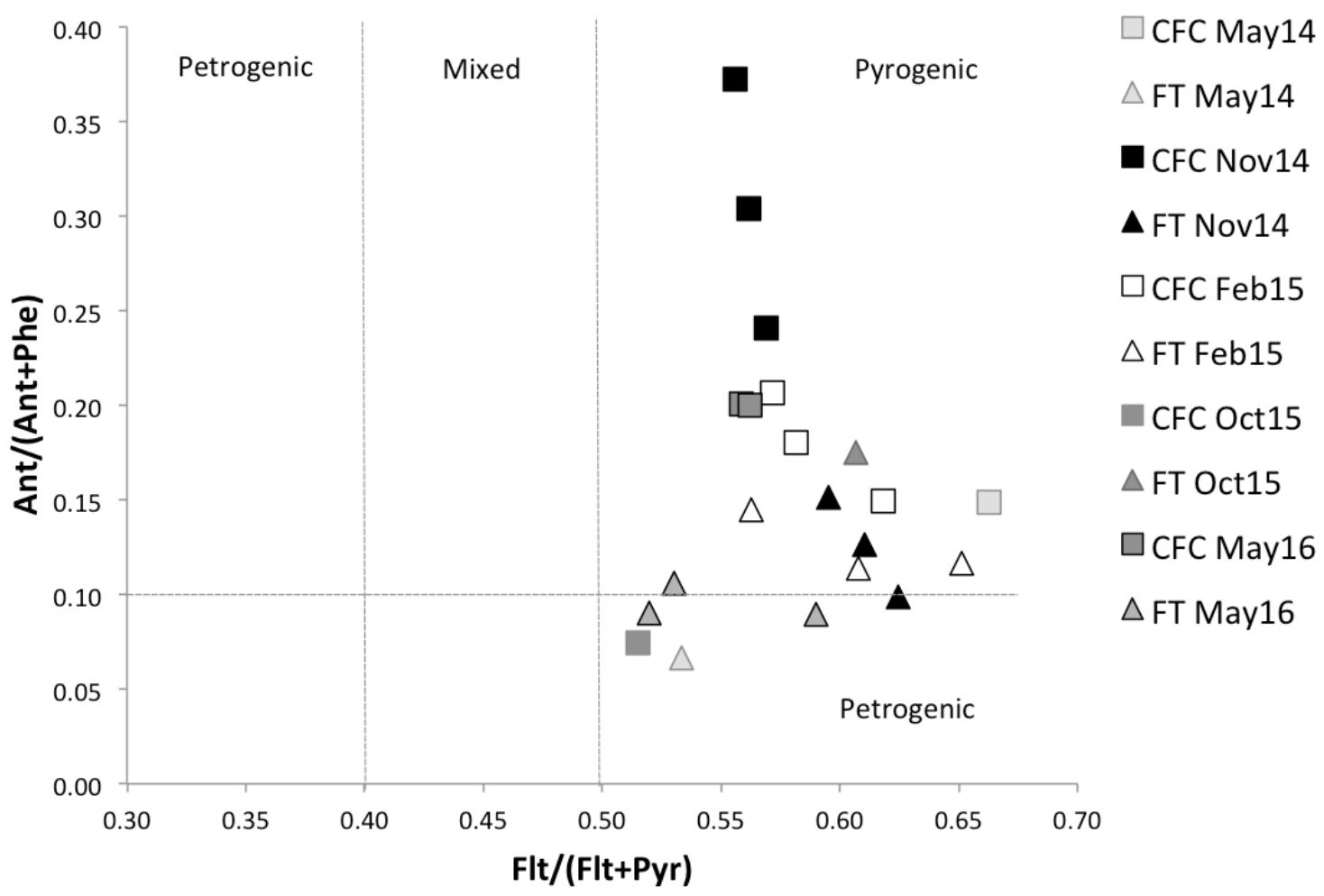

Fig. $6 \mathrm{Ant} /\left(\right.$ Ant+Phe) vs Flt/(Flt+Pyr) diagnostic ratios calculated in $\mathrm{SPM}_{\mathrm{CFC}}$ and SPM $\mathrm{FT}_{\mathrm{FT}}$. Dashed lines represent the limits of petrogenic/ pyrogenic domains after Yunker et al. (2002) 


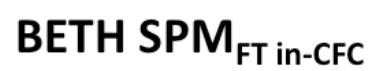

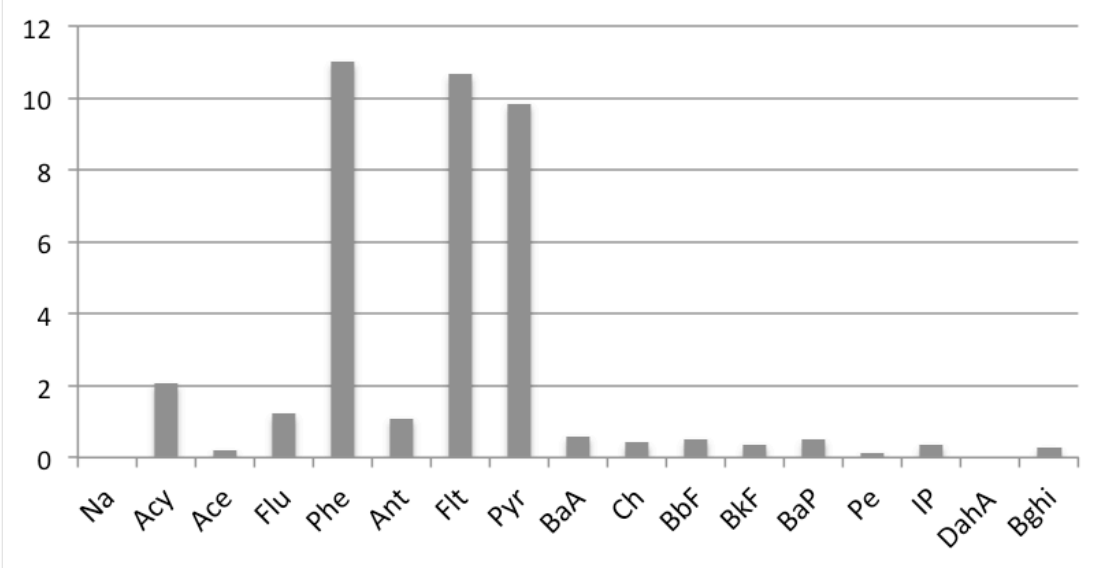

BETH SPM

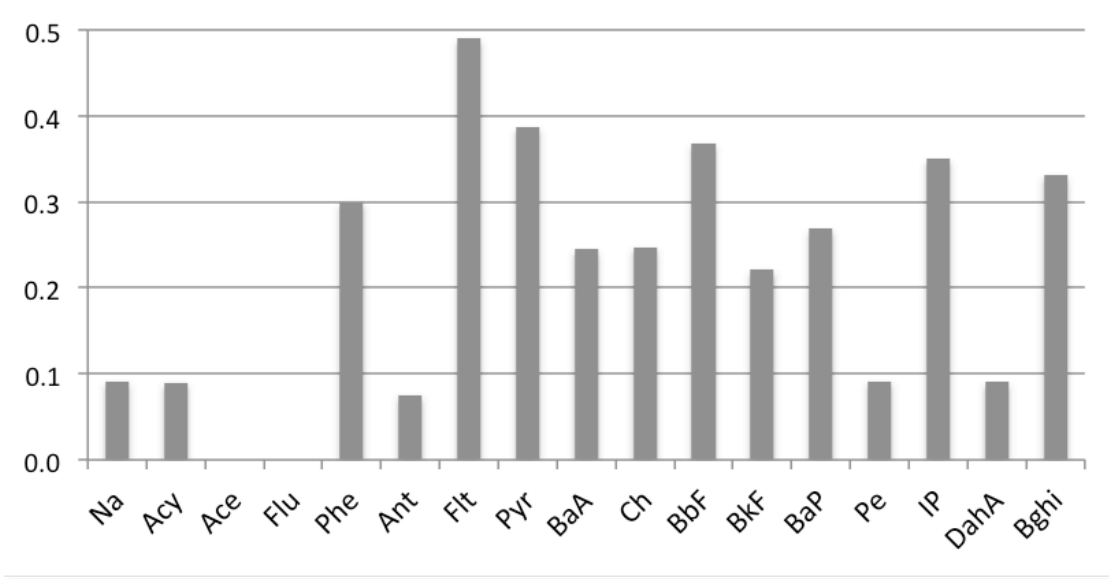

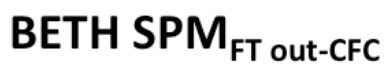

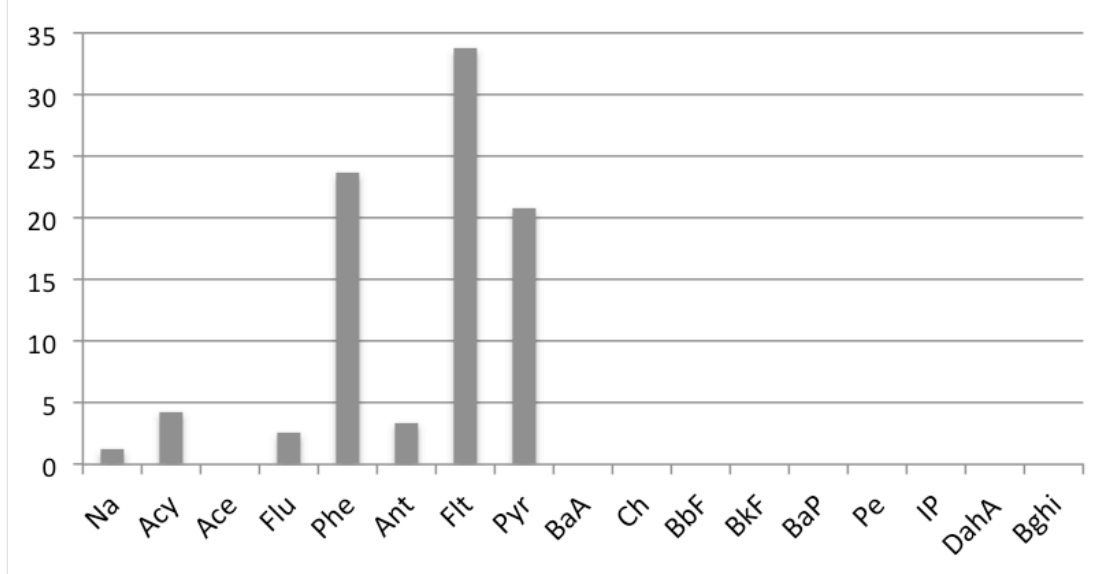

Fig. 7 Distributions of PAHs in $\mu g^{-1}$ in (a) $\operatorname{SPM}_{\mathrm{FT} \mathrm{In-CFC}}$ (b) the $\mathrm{SPM}_{\mathrm{CFC}}$, (c) the $\mathrm{SPM}_{\mathrm{FT} \text { Out-CFC }}$ 


\begin{tabular}{|c|c|c|c|c|c|c|c|c|c|c|c|c|c|c|c|c|c|}
\hline \multirow{2}{*}{$\begin{array}{l}\text { Date } \\
\text { Site }\end{array}$} & \multicolumn{2}{|c|}{ May 2014} & \multicolumn{3}{|c|}{ Nov 2014} & \multicolumn{3}{|c|}{ Feb 2015} & \multicolumn{4}{|c|}{ May 2015} & \multicolumn{2}{|c|}{ Oct 2015} & \multicolumn{2}{|c|}{ May 2016} & \multirow{2}{*}{$\begin{array}{r}\text { June } 2016 \\
\text { BETH }\end{array}$} \\
\hline & JOAB & BETH & BARB & JOAB & BETH & AUB & BARB & BETH & AUB & JOAB & BETH & $\mathrm{RICH}$ & AUB & $\mathrm{RICH}$ & AUB & $\mathrm{RICH}$ & \\
\hline Water discharge $\left(\mathrm{m}^{3} \mathrm{~s}^{-1}\right)$ & 1.5 & 1.4 & 22.4 & 22.4 & 50.5 & 49.4 & 49.2 & 49.4 & 23.5 & 11.2 & 11.2 & 23.5 & 1.5 & 1.5 & 120.0 & 120.0 & 29.5 \\
\hline Temperature $\left({ }^{\circ} \mathrm{C}\right)$ & 16.6 & 15.2 & 12.0 & 12.0 & 11.7 & 3.4 & 2.9 & 3.8 & 15.4 & 18.0 & 17.7 & 17.0 & 12.8 & 12.8 & 14.0 & 15.1 & 18.7 \\
\hline Turbidity (NTU) & 1.8 & 2.1 & 19.7 & 24.6 & 108.8 & 35.3 & 31.7 & 34.3 & 37.7 & 35.4 & 33.7 & 29.6 & 2.2 & 2.2 & 93.4 & 94.0 & 56.7 \\
\hline $\mathrm{EC}\left(\mu \mathrm{S} \mathrm{cm}^{-1}\right)$ & 1039 & 1019 & 904 & 845 & 548 & 535 & 574 & 594 & 563 & 617 & 616 & 697 & 710 & 710 & 358 & 405 & 521 \\
\hline SPM content $\left(\mathrm{mg} \mathrm{L}^{-1}\right)$ & 4.3 & 5.9 & 40.2 & 32.4 & 121.6 & 39.3 & 34.5 & 32.5 & 36.1 & 38.0 & 32.2 & 25.6 & 1.8 & 1.8 & 80.6 & 90.2 & 32.6 \\
\hline $\mathrm{d} 50(\mu \mathrm{m})$ & nd & nd & 15.1 & 14.9 & 11.3 & 5.4 & 4.9 & 5.2 & 9.5 & 10.0 & 7.7 & 13.7 & 9.6 & 15.5 & 7.9 & 11.3 & nd \\
\hline POC (\%) & 6.9 & 12.5 & 5.4 & 3.9 & 3.3 & 3.3 & 3.1 & 3.2 & 4.2 & 4.8 & 4.9 & 5.8 & nd & nd & 3.3 & 4.2 & 3.5 \\
\hline DOC $\left(\mathrm{mg} \mathrm{L}^{-1}\right)$ & 5.2 & 4.7 & 4.4 & 4.5 & 10.9 & 6.5 & 6.7 & 6.5 & 11.3 & 9.1 & 8.3 & 9.9 & 9.6 & 4.3 & 9.2 & 8.4 & 8.7 \\
\hline
\end{tabular}

Table 1 Physical-chemical parameters at each sampling campaigns: daily integrated water discharge $\left(\mathrm{m}^{3} \mathrm{~s}^{-1}\right)($ taken from the hydrometric station in MoyeuvreGrande for May and November 2014 and calculated from the continuous recorded water level values at BETH for the campaigns of 2015 and 2016 ), temperature $\left({ }^{\circ} \mathrm{C}\right)$, turbidity (NTU), electric conductivity $\mathrm{EC}\left(\mu \mathrm{S} \mathrm{cm}{ }^{-1}\right)$ measured on site and SPM concentration $\left(\mathrm{mg} \mathrm{L}^{-1}\right)$, decile 50 of the grain size distribution (d50 in $\left.\mu \mathrm{m}\right)$, DOC $\left(\mathrm{mg} \mathrm{L}^{-1}\right)$, POC (\% of SPM content) measured at the lab. 


\begin{tabular}{|c|c|c|c|c|c|c|c|c|c|c|c|c|c|c|c|c|c|}
\hline \multirow{2}{*}{$\begin{array}{l}\text { Date } \\
\text { Site }\end{array}$} & \multicolumn{2}{|c|}{ May 2014} & \multicolumn{3}{|c|}{ Nov 2014} & \multicolumn{3}{|c|}{ Feb 2015} & \multicolumn{4}{|c|}{ May 2015} & \multicolumn{2}{|c|}{ Oct 2015} & \multicolumn{2}{|c|}{ May 2016} & \multirow{2}{*}{$\begin{array}{c}\text { June } 2016 \\
\text { BETH }\end{array}$} \\
\hline & JOAB & ВЕТН & BARB & JOAB & ВETH & AUB & BARB & ВЕТН & AUB & JOAB & ВETH & RICH & AUB & RICH & AUB & RICH & \\
\hline PACs in $\mathrm{SPM}_{\mathrm{CFC}}$ & & & & & & & & & & & & & & & & & \\
\hline$\Sigma$ 16PAHs $\left(\mu \mathrm{g} \mathrm{g}^{-1}\right)$ & 27.69 & 3.99 & 6.07 & 5.38 & 5.25 & 2.54 & 3.72 & 5.08 & 2.45 & 3.77 & 3.36 & 3.74 & 5.17 & 7.03 & 2.01 & 4.20 & 3.56 \\
\hline$\Sigma$ O-PACs $\left(\mu \mathrm{gg}_{-}{ }^{1}\right)$ & 2.66 & 1.09 & 0.91 & 0.91 & 0.68 & 0.19 & 0.12 & 0.42 & 0.51 & 0.96 & 0.95 & 1.1 & 2.48 & 3.76 & 0.09 & 0.00 & 0.13 \\
\hline$\Sigma$ N-PACs $\left(\mu \mathrm{g} \mathrm{g}^{-1}\right)$ & 0.43 & 0.9 & 0.09 & 0.2 & 0.06 & 0.03 & $<\mathrm{LQ}$ & 0.05 & $<\mathrm{LQ}$ & 0.04 & 0.03 & 0.04 & 0.10 & 0.30 & 0.18 & 0.10 & 0.12 \\
\hline$\Sigma$ All PACs $\left(\mu \mathrm{g} \mathrm{g}^{-1}\right)$ & 30.77 & 5.99 & 7.07 & 6.49 & 5.98 & 2.76 & 3.84 & 5.55 & 2.96 & 4.77 & 4.35 & 4.88 & 7.75 & 11.09 & 2.28 & 4.30 & 3.81 \\
\hline Ant/(Ant+Phe) & 0.15 & 0.18 & 0.24 & 0.3 & 0.37 & 0.21 & 0.18 & 0.15 & 0.32 & 0.32 & 0.34 & 0.36 & & 0.07 & & 0.20 & 0.20 \\
\hline Flt/(Flt+Pyr) & 0.66 & 0.6 & 0.57 & 0.56 & 0.56 & 0.57 & 0.58 & 0.62 & 0.54 & 0.56 & 0.55 & 0.56 & 0.53 & 0.51 & 0.56 & 0.56 & 0.56 \\
\hline $\mathrm{BaA} /(\mathrm{BaA}+\mathrm{Ch})$ & & 0.52 & 0.53 & 0.53 & 0.54 & 0.56 & 0.57 & 0.57 & 0.5 & 0.52 & 0.52 & 0.53 & 0.49 & 0.49 & 0.46 & 0.50 & 0.50 \\
\hline $\mathrm{IP} /(\mathrm{IP}+\mathrm{Bghi})$ & & 0.63 & 0.55 & 0.55 & 0.57 & 0.6 & 0.62 & 0.62 & 0.52 & 0.53 & 0.54 & 0.54 & 0.55 & 0.52 & 0.51 & 0.51 & 0.51 \\
\hline 2-3 ring PAHs (\%) & $85 \%$ & $50 \%$ & $20 \%$ & $19 \%$ & $14 \%$ & $19 \%$ & $36 \%$ & $43 \%$ & $9 \%$ & $13 \%$ & $11 \%$ & $12 \%$ & $21 \%$ & $29 \%$ & $13 \%$ & $14 \%$ & $16 \%$ \\
\hline $\begin{array}{l}\text { 3-rings O-PACs } \\
(\%)\end{array}$ & $100 \%$ & $46 \%$ & $34 \%$ & $31 \%$ & $15 \%$ & $42 \%$ & $100 \%$ & $74 \%$ & $36 \%$ & $22 \%$ & $20 \%$ & $20 \%$ & $21 \%$ & $29 \%$ & $100 \%$ & & $100 \%$ \\
\hline PACs in $S_{F P}$ & & & & & & & & & & & & & & & & & \\
\hline$\Sigma$ 16PAHs $\left(\mu \mathrm{g} \mathrm{g}^{-1}\right)$ & 31.24 & 19.78 & 7.18 & 10.26 & 10.97 & 23.53 & 25.37 & 34.43 & 1.3 & 1.34 & 1.77 & 2.58 & 23.77 & 13.64 & 18.44 & 25.98 & 39.06 \\
\hline$\Sigma$ O-PACs $\left(\mu \mathrm{g} \mathrm{g}_{-}{ }^{1}\right)$ & 3.25 & 0.89 & 0.94 & 0.97 & 0.72 & 2.55 & 3.36 & 3.73 & 0.09 & 0.19 & $<\mathrm{LQ}$ & 0.11 & 3.30 & 5.43 & 1.89 & 4.07 & 3.93 \\
\hline$\Sigma$ N-PACs $\left(\mu \mathrm{g} \mathrm{g}^{-1}\right)$ & 1.78 & 29.41 & 0.12 & 0.11 & 0.12 & 0.11 & 0.26 & 0.14 & 0.16 & 0.23 & $<\mathrm{LQ}$ & 0.45 & $<\mathrm{LQ}$ & $<\mathrm{LQ}$ & $<\mathrm{LQ}$ & $<\mathrm{LQ}$ & 0.15 \\
\hline$\Sigma$ All PACs $\left(\mu \mathrm{g} \mathrm{g}^{-1}\right)$ & 36.27 & 50.08 & 8.24 & 11.34 & 11.81 & 26.2 & 28.98 & 38.3 & 1.55 & 1.77 & 1.77 & 3.14 & 27.07 & 19.07 & 20.33 & 30.05 & 43.14 \\
\hline Ant/(Ant+Phe) & 0.07 & & 0.15 & 0.1 & 0.13 & 0.12 & 0.15 & 0.11 & & & & & 0.06 & 0.17 & 0.09 & 0.11 & 0.09 \\
\hline Flt/(Flt+Pyr) & 0.53 & 0.59 & 0.6 & 0.62 & 0.61 & 0.65 & 0.56 & 0.61 & 0.58 & & & 0.57 & 0.58 & 0.61 & 0.59 & 0.53 & 0.52 \\
\hline $\mathrm{BaA} /(\mathrm{BaA}+\mathrm{Ch})$ & & & 0.55 & 0.6 & 0.59 & & & & 0.59 & & & 0.59 & & & 0.59 & 0.54 & 0.59 \\
\hline $\mathrm{IP} /(\mathrm{IP}+\mathrm{Bghi})$ & & & 0.55 & 0.57 & 0.62 & & 0.65 & 0.56 & 0.61 & & & 0.6 & & & 0.57 & 0.52 & 0.56 \\
\hline 2-3 ring PAHs (\%) & $57 \%$ & $33 \%$ & $28 \%$ & $31 \%$ & $34 \%$ & $79 \%$ & $74 \%$ & $84 \%$ & $7 \%$ & $25 \%$ & $28 \%$ & $24 \%$ & $70 \%$ & $55 \%$ & $49 \%$ & $49 \%$ & $40 \%$ \\
\hline 3-ring O-PACs (\%) & $100 \%$ & $100 \%$ & $52 \%$ & $63 \%$ & $90 \%$ & $96 \%$ & $96 \%$ & $100 \%$ & $100 \%$ & $100 \%$ & & $100 \%$ & $100 \%$ & $100 \%$ & $100 \%$ & $89 \%$ & $100 \%$ \\
\hline
\end{tabular}

Table 2 PAC concentrations in $\mathrm{SPM}_{\mathrm{CFC}}$ and $\mathrm{SPM}_{\mathrm{FT}}\left(\mu \mathrm{g} \mathrm{g}^{-1} \mathrm{dw}\right)$ and molecular ratios of PACs. <LQ: under the limit of quantification. 


\begin{tabular}{|c|c|c|c|c|c|}
\hline Sample name & & SPM content $\left(\mathrm{mg} \mathrm{L}^{-1}\right)$ & $\Sigma 16 \mathrm{PAHs}$ EPA & $\Sigma \mathrm{O}-\mathrm{PACs}$ & ¿AllPACs \\
\hline \multirow{3}{*}{ AUB May 2016} & $\mathrm{SPM}_{\mathrm{FT} \mathrm{In-} \mathrm{CFC}}$ & 83.14 & 18.44 & 1.89 & 20.33 \\
\hline & $\mathrm{SPM}_{\mathrm{CFC}}$ & & 2.01 & 0.09 & 2.28 \\
\hline & $\mathrm{SPM}_{\mathrm{FT} \text { Out-CFC }}$ & 17.96 & 16.71 & 5.30 & 22.00 \\
\hline \multirow{3}{*}{ RICH May 2016} & $\mathrm{SPM}_{\mathrm{FT} \mathrm{In-} \mathrm{CFC}}$ & 94.60 & 25.98 & 4.07 & 30.05 \\
\hline & $\mathrm{SPM}_{\mathrm{CFC}}$ & & 4.20 & 0.00 & 4.30 \\
\hline & $\mathrm{SPM}_{\mathrm{FT} \text { Out-CFC }}$ & 16.84 & 26.67 & 4.00 & 30.67 \\
\hline \multirow{3}{*}{ BETH June 2016} & $\mathrm{SPM}_{\mathrm{FT} \mathrm{In-} \mathrm{CFC}}$ & 23.47 & 39.06 & 3.93 & 43.14 \\
\hline & $\mathrm{SPM}_{\mathrm{CFC}}$ & & 3.56 & 0.13 & 3.81 \\
\hline & SPM $_{\text {FT Out-CFC }}$ & 4.67 & 89.76 & 18.01 & 107.77 \\
\hline
\end{tabular}

Table 3 PAC concentrations in $\mu \mathrm{g} \mathrm{g}^{-1}$ in the $\mathrm{SPM}_{\mathrm{CFC}}$ and in the SPM collected by filtration of the waters entering the CFC (SPM $\mathrm{FT}_{\mathrm{F}-\mathrm{CFC}}$ ) and of the waters collected at the outlet of the CFC (SPM FT Out-CFC). This campaign was performed at AUB, RICH and BETH in May-June 2016. 


\begin{tabular}{|c|c|c|c|c|}
\hline Authors & River & Sampling collection & $\begin{array}{c}\text { Particulate } \\
\text { PAHs }\left(\mu \mathrm{g} \mathrm{g}^{-1}\right)\end{array}$ & $\begin{array}{c}\text { LMW2-3 } \\
\text { /HMW4-6 }\end{array}$ \\
\hline Chiffre et al 2015 & Rivière Jura & Sediment trap & $0.75-2.50$ & $0.1-0.16$ \\
\hline Wölz et al 2010 & Neckars and Rhine & $\mathrm{CFC}$ & $1.00-5.00$ & $0.08-0.1$ \\
\hline Le Meur et al 2017 & Moselle River & $\mathrm{CFC}$ & $2.00-8.00$ & $0.06-0.36$ \\
\hline Countway et al 2003 & York River & $\begin{array}{l}\text { Glass-fiber filters } 1 \mu \mathrm{m} \\
\text { pressurized filtration }\end{array}$ & $0.23-1.03$ & $0.05-0.31$ \\
\hline Ko and Baker 2004 & Susquehanna River, USA & $\begin{array}{l}\text { Glass-fiber filters } 1 \mu \mathrm{m} \\
\text { pressurized filtration }\end{array}$ & $3.00-9.00$ & 0.20 \\
\hline $\begin{array}{l}\text { Mitra and Bianchi } \\
2003\end{array}$ & Mississippi & Glass-fiber filters $0.7 \mu \mathrm{m}$ & $0.065-7.00$ & $0.002-0.006$ \\
\hline Sun et al 2009 & Yellow River & Glass-fiber filters $0.7 \mu \mathrm{m}$ & $0.500-10.50$ & $0.1-1.3$ \\
\hline Maioli et al 2011 & Brasilian estuaries & Glass-fiber filters $1.2 \mu \mathrm{m}$ & $0.170-1.80$ & $0.05-2.63$ \\
\hline Deng et al 2006 & Xijiang River, South China & Glass-fiber filters & $0.04-0.66$ & $0.59-2.49$ \\
\hline Luo et al. 2004 & Pearl River Estuary, China & Glass-fiber filters $0.7 \mu \mathrm{m}$ & $1.80-89.00$ & $0.87-4.8$ \\
\hline Guo et al. 2007 & Daliao River, China & PFFE - $0.45 \mu \mathrm{m}$ & $0.3-239$ & $0.02-25$ \\
\hline This study & Orne River, France & Glass-fiber filters $0.7 \mu \mathrm{m}$ & $1.30-39.06$ & $0.1-5.25$ \\
\hline This study & Orne River, France & $\mathrm{CFC}$ & $2.01-7.03$ & $0.1-0.98$ \\
\hline
\end{tabular}

Table 4 Comparison of PAH concentrations and LMW/HMW ratios in SPM according to the sampling methods, data extracted from literature. 
S1: Analyzed compounds with their corresponding Internal standard compounds and specific ions selected for quantification and their limit of quantification (LOQ) associated calculated for $1 \mathrm{mg}$ sample.

\begin{tabular}{|c|c|c|}
\hline Internal Standard [m/z] & Compound $[\mathrm{m} / \mathrm{z}]$ & $\operatorname{LOQ}\left(\mu \mathrm{g} \mathrm{g}^{-1}\right)$ \\
\hline \multicolumn{3}{|l|}{ РAH } \\
\hline$\left[{ }^{2} \mathrm{H}_{8}\right]$ Naphtalene [136] & Naphtalene [128] & 0.12 \\
\hline \multirow{3}{*}[{}^{2}\mathrm{H}_{10}]{ Acenaphtylene $[164]$} & Acenaphtylene [152] & 0.12 \\
\hline & Acenaphthene [153] & 0.12 \\
\hline & Fluorene [166] & 0.06 \\
\hline \multirow[t]{2}{*}[{}^{2}\mathrm{H}_{10}]{ Phenanthrene $[188]$} & Phenanthrene [178] & 0.06 \\
\hline & Anthracene [178] & 0.06 \\
\hline \multirow[t]{2}{*}[{}^{2}\mathrm{H}_{10}]{ Pyrene $[212]$} & Fluoranthene [202] & 0.06 \\
\hline & Pyrene [202] & 0.06 \\
\hline \multirow[t]{4}{*}[{}^{2}\mathrm{H}_{12}]{ Chysene $[240]$} & Benz[a]anthracene [228] & 0.06 \\
\hline & Chrysene [228] & 0.06 \\
\hline & Benzo[b]fluoranthene [252] & 0.06 \\
\hline & Benzo[k]fluoranthene [252] & 0.06 \\
\hline \multirow{5}{*}[{}^{2}\mathrm{H}_{12}]{ Perylene $[264]$} & Benzo[a]pyrene [252] & 0.06 \\
\hline & Perylene [252] & 0.06 \\
\hline & Indeno[1,2,3-c,d]pyrene [276] & 0.06 \\
\hline & Dibenzo(ah)anthracene [278] & 0.12 \\
\hline & Benzo[ghi]perylene [276] & 0.06 \\
\hline \multicolumn{3}{|l|}{ O-PAC } \\
\hline$\left[{ }^{2} \mathrm{H}_{10}\right]$ Acenaphtylene [164] & Dibenzofuran [168] & 0.06 \\
\hline \multirow[t]{4}{*}[{}^{2}\mathrm{H}_{8}]{9 HFluorenone [188] } & 9H-fluorenone [180] & 0.06 \\
\hline & Perinaphtenone [152] & 0.12 \\
\hline & Anthraquinone [208] & 0.06 \\
\hline & Cyclopenta(def)phenanthrone[204] & 0.12 \\
\hline \multirow[t]{2}{*}[{}^{2}\mathrm{H}_{10}]{ Pyrene $[212]$} & Methylanthracene-9.10-dione [165] & 0.12 \\
\hline & Benzo(a)fluorenone [230] & 0.12 \\
\hline \multirow[t]{4}{*}[{}^{2}\mathrm{H}_{12}]{ Chysene $[240]$} & Benzanthrone [258] & 0.06 \\
\hline & Benzoanthracenedione [258] & 0.06 \\
\hline & Naphtacene-5.12-dione [228] & 0.06 \\
\hline & Benzo(cd)pyrenone [254] & 0.12 \\
\hline \multicolumn{3}{|l|}{ N-PAC } \\
\hline$\left[{ }^{2} \mathrm{H}_{7}\right]$ Quinoline [136] & Quinoline [129] & 0.12 \\
\hline \multirow[t]{3}{*}[{}^{2}\mathrm{H}_{8}]{9 HFluorenone $[188]$} & Benzo(h)quinoline [179] & 0.06 \\
\hline & Acridine [179] & 0.06 \\
\hline & Carbazole [167] & 0.06 \\
\hline \multirow{2}{*}[{}^{2}\mathrm{H}_{10}]{ Pyrene [212] } & Benzo(c)acridine [229] & 0.06 \\
\hline & \begin{tabular}{|l|} 
Nitropyrene [] \\
\end{tabular} & 0.12 \\
\hline
\end{tabular}

S2: Recoveries of external standards. Average and standard deviations evaluated for 34 samples (CFC and FT).

\begin{tabular}{|l|l|}
\hline External Standard [m/z] & Mean \pm SD (\%) \\
\hline$\left[{ }^{2} \mathrm{H}_{8}\right]$ Dibenzofuran [176] & $83.6 \pm 17.0$ \\
\hline$\left[{ }^{2} \mathrm{H}_{10}\right]$ Fluorene [176] & $93.5 \pm 13.1$ \\
\hline$\left[{ }^{2} \mathrm{H}_{10}\right]$ Anthracene [188] & $91.8 \pm 12.0$ \\
\hline$\left[{ }^{2} \mathrm{H}_{8}\right]$ Anthraquinone [216] & $77.9 \pm 17.6$ \\
\hline$\left[{ }^{2} \mathrm{H}_{10}\right]$ Fluoranthène [212] & $92.5 \pm 12.4$ \\
\hline$\left[{ }^{2} \mathrm{H}_{12}\right]$ Benzo[ghi]perylene [288] & $94.5 \pm 16.8$ \\
\hline
\end{tabular}

